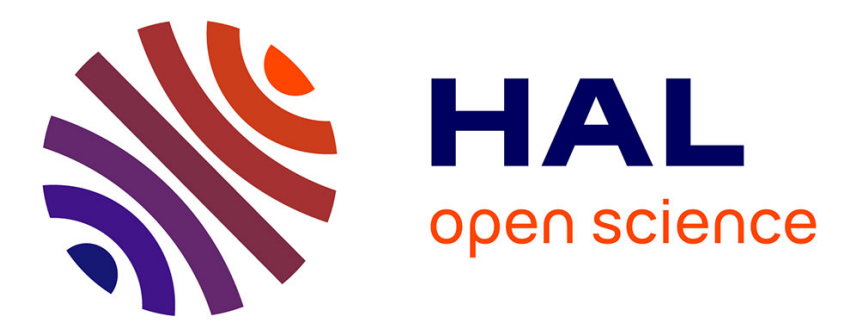

\title{
Exploration of Uncharted 3PES Territory for [Ru(bpy)3]2+: A New 3MC Minimum Prone to Ligand Loss Photochemistry
}

Adrien Soupart, Fabienne Alary, Jean-Louis Heully, Elliott I.P. Paul, Isabelle M. Dixon

\section{To cite this version:}

Adrien Soupart, Fabienne Alary, Jean-Louis Heully, Elliott I.P. Paul, Isabelle M. Dixon. Exploration of Uncharted 3PES Territory for $[\mathrm{Ru}(\mathrm{bpy}) 3] 2+$ : A New 3MC Minimum Prone to Ligand Loss Photochemistry. Inorganic Chemistry, 2018, 57, 6, pp.3192-3196. 10.1021/acs.inorgchem.7b03229 . hal-01741450

\author{
HAL Id: hal-01741450 \\ https://hal.science/hal-01741450
}

Submitted on 18 Feb 2020

HAL is a multi-disciplinary open access archive for the deposit and dissemination of scientific research documents, whether they are published or not. The documents may come from teaching and research institutions in France or abroad, or from public or private research centers.
L'archive ouverte pluridisciplinaire HAL, est destinée au dépôt et à la diffusion de documents scientifiques de niveau recherche, publiés ou non, émanant des établissements d'enseignement et de recherche français ou étrangers, des laboratoires publics ou privés. 


\title{
Exploration of uncharted ${ }^{3} \mathrm{PES}$ territory for $\left[\operatorname{Ru}(\mathrm{bpy})_{3}\right]^{2+}:$ a new ${ }^{3} \mathrm{MC}$ minimum prone to ligand loss photochemistry
}

\author{
Adrien Soupart, ${ }^{\#}$ Fabienne Alary, ${ }^{\#}$ Jean-Louis Heully, ${ }^{\#}$ Paul I. P. Elliott, ${ }^{\S \pi^{*}}$ and Isabelle M. Dixon ${ }^{\# *}$ \\ \#Laboratoire de Chimie et Physique Quantiques, Université de Toulouse, CNRS, 118 route de Narbonne, \\ 31062 Toulouse, France. \\ ${ }^{\S}$ Department of Chemistry, University of Huddersfield, Queensgate, Huddersfield, HD1 3DH, UK. \\ ${ }^{\natural}$ Centre for Functional Materials, University of Huddersfield, Queensgate, Huddersfield, HD1 3DH, \\ UK.
}

\begin{abstract}
We have identified a new ${ }^{3} \mathrm{MC}$ state bearing two elongated $\mathrm{Ru}-\mathrm{N}$ bonds to the same ligand in $\left[\mathrm{Ru}(\mathrm{bpy})_{3}\right]^{2+}$. This DFT-optimized structure is a local minimum on the ${ }^{3} \mathrm{PES}$. This distal MC state $\left({ }^{3} \mathrm{MC}_{\text {cis }}\right)$ is destabilized by less than $2 \mathrm{kcal} / \mathrm{mol}$ with respect to the classical $\mathrm{MC}$ state $\left({ }^{3} \mathrm{MC}_{\text {trans }}\right)$, and energy barriers to populate ${ }^{3} \mathrm{MC}_{\text {cis }}$ and ${ }^{3} \mathrm{MC}_{\text {trans }}$ from the ${ }^{3} \mathrm{MLCT}$ state are similar according to nudged elastic band minimum energy path calculations. Distortions in the classical ${ }^{3} \mathrm{MC}_{\text {trans }}$, i.e. elongation of two Ru-N bonds towards two different bpy ligands, are not expected to favour the formation of ligandloss photoproducts. On the contrary, the new ${ }^{3} \mathrm{MC}_{c i s}$ could be particularly relevant in the photodegradation of $\mathrm{Ru}(\mathrm{II})$ polypyridine complexes.
\end{abstract}

For the last four decades, $\left[\mathrm{Ru}(\mathrm{bpy})_{3}\right]^{2+}$ has been at the heart of inorganic photochemistry and has been thoroughly studied for its intrinsic photophysical properties, which arise from the interplay of two excited states of different electronic nature. ${ }^{1}$ Irradiation in the visible region populates a singlet metalto-ligand charge transfer state $\left({ }^{1} \mathrm{MLCT}\right)$, which populates a ${ }^{3} \mathrm{MLCT}$ state following quantitative intersystem crossing. This charge transfer state can deactivate radiatively (the complex is phosphorescent at room temperature), non radiatively, ${ }^{2}$ or via the population of a metal-centred state $\left({ }^{3} \mathrm{MC}\right)$. This ${ }^{3} \mathrm{MC}$ state is by nature highly distorted with respect to the ground state geometry, which is thought to be related to its capacity to quench the ${ }^{3}$ MLCT luminescence through direct crossing with the reactant's ground state surface or through photoreactivity. ${ }^{1}$ But this photoreactivity, resulting in the loss of bpy, seems unlikely to be due to classical axially-elongated ${ }^{3} \mathrm{MC}$ states repelling two pyridines from two distinct bpy ligands.

The recent computational identification of several ${ }^{3} \mathrm{MC}$ minima displaying various modes of elongations in heteroleptic tris(bidentate) $\mathrm{Ru}(\mathrm{II})$ complexes evidenced the existence of novel ${ }^{3} \mathrm{MC}$ states, in which bond elongations are focused towards a single bidentate ligand (hence involving elongation of two Ru-N bonds $c$ is to one another. This class of $\mathrm{MC}$ state is called ${ }^{3} \mathrm{MC}_{c i s}$ hereafter). This type of ${ }^{3} \mathrm{MC}$ minimum, only once previously reported in a photochromic $\mathrm{Ru}$ sulfoxide complex, ${ }^{3}$ has been shown to be particularly prone to eject a bidentate ligand. ${ }^{4}$ Very recently this type of geometry has also been reported to be involved in $\Delta / \Lambda$ isomerism, and its involvement in ligand loss was suggested. ${ }^{5}$ In relation with the reported (relative) photoinstability of the archetypical $\left[\mathrm{Ru}(\mathrm{bpy})_{3}\right]^{2+6,7,8,9,10}$ we were interested in testing the hypothesis that such MC states had a more general existence and could also be found in homoleptic tris(bidentate) complexes. The aim of this work was therefore to search for such a ${ }^{3} \mathrm{MC}_{c i s}$ minimum on 
the triplet excited potential energy surface of $\left[\mathrm{Ru}(\mathrm{bpy})_{3}\right]^{2+}$ and we report its successful characterization here. We show that this new ${ }^{3} \mathrm{MC}_{\text {cis }}$ state is only marginally higher in energy than the classical axiallyelongated ${ }^{3} \mathrm{MC}$ state, and that both ${ }^{3} \mathrm{MC}$ states have a similar barrier to their population from the ${ }^{3} \mathrm{MLCT}$ state. Thus, these novel ${ }^{3} \mathrm{MC}_{c i s}$ states are likely to have significant involvement in the photophysics and photochemistry of $\left[\mathrm{Ru}(\mathrm{bpy})_{3}\right]^{2+}$-type complexes. We may therefore need to fundamentally reassess our presumptions of how photorelease of bpy and other ligands occurs in this class of complexes, in search for a better photoreactive ${ }^{3} \mathrm{MC}$ candidate.

Experimental background. In the 1970 s, $\left[\mathrm{Ru}(\mathrm{bpy})_{3}\right]^{2+}$ was reported to undergo photolysis in the presence of coordinating solvents (e.g. water or acetonitrile) ${ }^{6}$ or ions (e.g. chloride ${ }^{7,10}$ or thiocyanato $^{8}$ ). This photodegradation phenomenon was specifically studied in particularly unfavourable conditions $\left(0.1 \mathrm{M} \mathrm{HCl}\right.$ at $\left.95^{\circ} \mathrm{C}\right)$ in order to allow the complete characterization and quantification of photoproducts. ${ }^{6,11}$ In terms of mechanism, to our knowledge, no structural data is available on ${ }^{3} \mathrm{MC}$ states of $\mathrm{Ru}(\mathrm{II})$ complexes, which are short-lived species. The population of such ${ }^{3} \mathrm{MC}$ states has been recently evidenced through characteristic signatures obtained in transient absorption spectroscopy ${ }^{12,13}$ and time-resolved infrared spectroscopy. ${ }^{14,15,16}$ But the fact that $\kappa^{1}$-bpy intermediates bearing a monodentate bpy ligand are obtained ${ }^{10,11,17}$ leads us to think that a specific ${ }^{3} \mathrm{MC}$ state is distorted in such a way as to allow for this, in line with the postulated dissociative mechanism. ${ }^{17,18}$

Methodology. In order to rationalize the photoreactivity of ruthenium complexes, one needs to map the topology of their lowest triplet potential energy surface $\left({ }^{3} \mathrm{PES}\right)$. Once the minima are localized and identified, the quantification of the energy barrier that is encountered by the system along the minimum energy path (MEP) is highly informative as it is related to the ease with which one triplet state populates another. In addition, the localization of singlet/triplet minimum energy crossing points (MECPs) is crucial because these points lead the system to closed-shell species that will either repopulate reactant GS or, according to Wigner rules, react with solvent and form the photoproduct (the latter being out of the scope of this work). ${ }^{18}$ This work therefore reports minima, MEPs and MECPs for $\left[\mathrm{Ru}(\mathrm{bpy})_{3}\right]^{2+}$ in $\mathrm{MeCN}$ solution, following the same computational procedure as the one recently used to establish the ${ }^{3}$ MLCT- ${ }^{3} \mathrm{MC}$ energy barrier. ${ }^{19}$ Only a limited number of mechanistic theoretical studies have highlighted the crucial role of distorted ${ }^{3} \mathrm{MC}$ states in photoreactive $\mathrm{Ru}$ (II) complexes, $3,4,5,20,21,22,23,24,25,26,27,28,29,30,31$ but only three of these describe ${ }^{3} \mathrm{MC}$ states displaying elongations towards both bonds to the same bidentate ligand. ${ }^{3,4,5}$

Computational methods. This study was performed in solvent (MeCN, as modelled by SMD) ${ }^{32}$ since solvent significantly stabilizes ${ }^{3}$ MLCT states. ${ }^{19}$ Geometry optimizations were performed with Orca $3^{33}$ using the B3LYP functional, ${ }^{34,35}$ a relativistic small-core pseudopotential on Ru (SD28), ${ }^{36}$ the def2$\operatorname{TZVP}(-\mathrm{f})$ basis set, ${ }^{37}$ and the empirical D3 dispersion correction. ${ }^{38,39}$ The restricted Kohn-Sham formalism was used for ground states, while its unrestricted analogue was used for triplet states. SCF convergence was achieved using the DIIS algorithm followed by a semi-quadratic SOSCF converger. Geometries of the minima in solvent were optimized starting from the gas phase ones. Geometries of the MECPs were optimized starting from the geometries of the corresponding ${ }^{3} \mathrm{MC}$ states in $\mathrm{MeCN}$. Frequency calculations were run at the same level of theory and the absence of imaginary frequencies ascertained the nature of these points as minima. Mulliken spin densities on Ru were used as a straightforward descriptor of the electronic nature of the triplet excited state $\left(\sim 1\right.$ for a ${ }^{3}$ MLCT state, $\sim 1.8$ for a ${ }^{3} \mathrm{MC}$ state) and a full orbital analysis was conducted using Gabedit ${ }^{40}$ to confirm the localization of the unpaired electrons. MEPs were optimized in SMD-MeCN with the nudged elastic band (NEB) method $^{41,42}$ using a python module developed in the Clancy group that is interfaced with Orca. ${ }^{43}$ A 10frame initial path was prepared by interpolating start and end geometries using the IDPP method. ${ }^{44}$ 
Minima. Up to now, the lowest triplet excited potential energy surface of $\left[\mathrm{Ru}(\mathrm{bpy})_{3}\right]^{2+}$ was known to display two minima: a minimum of MLCT nature in the region of the GS equilibrium geometry, and a minimum of $\mathrm{MC}$ nature obtained after manual elongation of two trans $\mathrm{Ru}-\mathrm{N}$ bonds (hereafter called ${ }^{3} \mathrm{MC}_{\text {trans }}$ to highlight the elongation of two trans $\mathrm{Ru}-\mathrm{N}$ bonds). ${ }^{45,46}$ The rationale behind this strategy of manual distortion was guided by the ground state molecular orbitals, which indicated that the lowest of the two $e_{\mathrm{g}}$-type orbitals was of the $d_{\mathrm{z} 2}$-type (the terminology $d_{\mathrm{z} 2}$-like and $d_{\mathrm{x} 2-\mathrm{y} 2}$-like is employed for the sake of clarity, although it is not related to the actual axis systems of the states). The population of this $\mathrm{d}_{\mathrm{z} 2}$-like orbital in the triplet excited state would thus result in the aforementioned bond elongations. The resulting trans-elongated minimum is considered to be the classical ${ }^{3} \mathrm{MC}$ state. Initially optimized under $\mathrm{C}_{2}$ symmetry constraints in vacuum to reduce the computational cost, ${ }^{45}$ this $\mathrm{MC}$ minimum is here more distorted but the characteristic elongation of two trans $\mathrm{Ru}-\mathrm{N}$ bonds is maintained $(2.42$ and $2.53 \AA$, Figure $1 \&$ Table S1). In MeCN solvent (SMD), the $\mathrm{GS}^{3}{ }^{3} \mathrm{MC}_{\text {trans }}$ gap is $2.21 \mathrm{eV}(51.0 \mathrm{kcal} / \mathrm{mol})$ while the ${ }^{3} \mathrm{MLCT}^{3} \mathrm{MC}_{\text {trans }}$ gap is $0.18 \mathrm{eV}(4.2 \mathrm{kcal} / \mathrm{mol}) .{ }^{19}$ These gaps are in good agreement with previous reports. $^{12}$

Figure 1: Structures of optimized ${ }^{3} \mathrm{MC}_{\text {trans }}$ and ${ }^{3} \mathrm{MC}_{\text {cis }}$ (B3LYP-D3, SMD-MeCN; Ru label not shown). $\mathrm{Ru}-\mathrm{N}$ distances in angstroms.

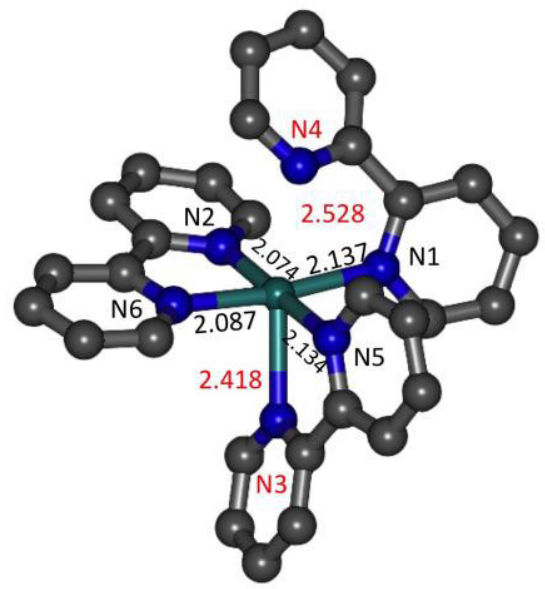

${ }^{3} \mathrm{MC}_{\text {trans }}$

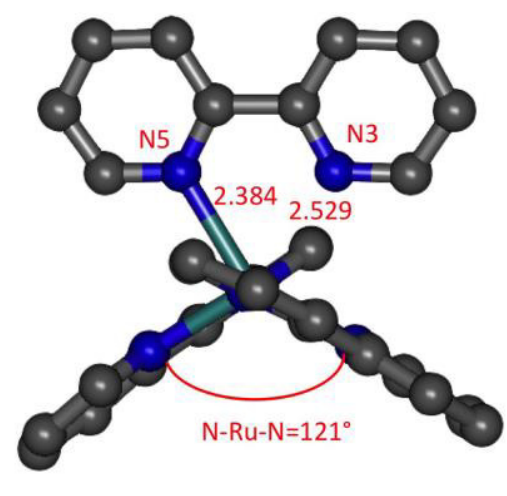

${ }^{3} \mathrm{MC}_{\text {cis }}$ side view

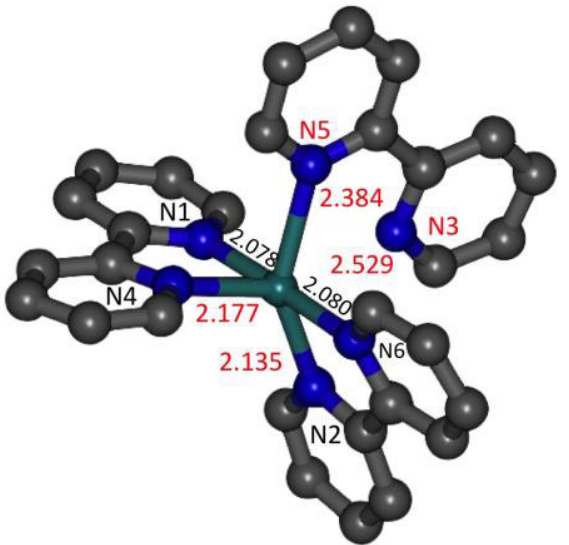

${ }^{3} \mathrm{MC}_{\text {cis }}$ top view

A possible distal cis-elongated ${ }^{3} \mathrm{MC}$ state was searched for by building a starting geometry with two elongated $\mathrm{Ru}-\mathrm{N}$ distances of ca. $2.5 \AA$ involving a single bpy ligand, while keeping the other two bpy ligands at more classical $\mathrm{Ru}-\mathrm{N}$ distances $(2.08-2.18 \AA$ ). The angle between the mean planes of these two ligands was also increased to ca. $130^{\circ}$ to mimic the flattened geometry observed in a related series of bi(triazolyl) (btz) complexes. ${ }^{4}$ This geometry gently optimized to a minimum, as testified by the absence of imaginary frequencies in the calculation. Due to the steric clash between $\alpha$-hydrogen atoms in bpy ligands, the equilibrium geometry of the $\left[\mathrm{Ru}(\mathrm{bpy})_{3}\right]^{2+}$ distal ${ }^{3} \mathrm{MC}\left({ }^{3} \mathrm{MC}_{c i s}\right)$ is not as flat as with btz (which does not induce such a steric clash), and a final interligand angle of $121^{\circ}$ is observed in the opposite quadrant with respect to the distal ligand (Figure 1). The distal bpy displays final $\mathrm{Ru}-\mathrm{N}$ distances of 2.38 and $2.53 \AA$. The other two bpy ligands display final $\mathrm{Ru}-\mathrm{N}$ distances of 2.09 and $2.17 \AA$. Note that $\mathrm{Ru}-\mathrm{N} 1$ and $\mathrm{Ru}-\mathrm{N} 5$ are necessarily elongated in ${ }^{3} \mathrm{MC}_{\text {trans }}$ as a consequence of the major elongations observed on the two attached pyridines (Ru-N4 and Ru-N3). On the other hand, Ru-N4 (and to a lesser extent $\mathrm{Ru}-\mathrm{N} 2$ ) are elongated in ${ }^{3} \mathrm{MC}_{c i s}$ as a result of direct antibonding interactions with two lobes of the $\mathrm{d}_{\mathrm{x} 2-\mathrm{y} 2}$-like $\mathrm{d} \sigma^{*}$ orbital. Remarkably, the distal ${ }^{3} \mathrm{MC}_{c i s}$ state is only $0.08 \mathrm{eV}$ destabilized $(1.9 \mathrm{kcal} / \mathrm{mol})$ with respect to the classical ${ }^{3} \mathrm{MC}_{\text {trans }}$ state. Overall the ${ }^{3} \mathrm{MC}_{c i s}$ state displays four 
elongated $\mathrm{Ru}-\mathrm{N}$ bonds (two elongations of which are more pronounced) with respect to the GS geometry, and results from the occupation of a $\mathrm{d}_{\mathrm{x} 2-\mathrm{y} 2}$-like antibonding orbital (Figure 2).

As shown on Figure 3, the singly occupied natural orbitals of these two ${ }^{3} \mathrm{MC}$ minima, ${ }^{3} \mathrm{MC}_{\text {trans }}$ and ${ }^{3} \mathrm{MC}_{c i s}$, display clear $\mathrm{d}_{\mathrm{z} 2}$-like and $\mathrm{d}_{\mathrm{x} 2-\mathrm{y} 2}$-like features that are responsible for the observed geometric distortions in these excited states. These d-orbital contributions match those for singly occupied natural orbitals for ${ }^{3} \mathrm{MC}$ states for $\left[\mathrm{Ru}\left(\mathrm{N}^{\wedge} \mathrm{N}\right)(\mathrm{btz})_{2}\right]^{2+}$ complexes reported recently $\left(\mathrm{N}^{\wedge} \mathrm{N}=\right.$ bpy, 4-(pyrid-2-yl)$1,2,3$-triazole) ${ }^{4}$

Figure 2. Schematic antibonding interactions in the classical ${ }^{3} \mathrm{MC}_{\text {trans }}\left(\mathrm{d}_{\mathrm{z} 2}\right.$-like, left $)$ and in the new ${ }^{3} \mathrm{MC}_{c i s}\left(\mathrm{~d}_{\mathrm{x} 2-\mathrm{y} 2}\right.$-like, right) minima ( $\mathrm{Ru}$ atom not shown). The dashed lines signify the approximate planes of the two other bpy ligands for ${ }^{3} \mathrm{MC}_{c i s}$. Remarkable $\mathrm{Ru}-\mathrm{N}$ distances and $\mathrm{N}-\mathrm{Ru}-\mathrm{N}$ angles with B3LYPD3 in SMD-MeCN.
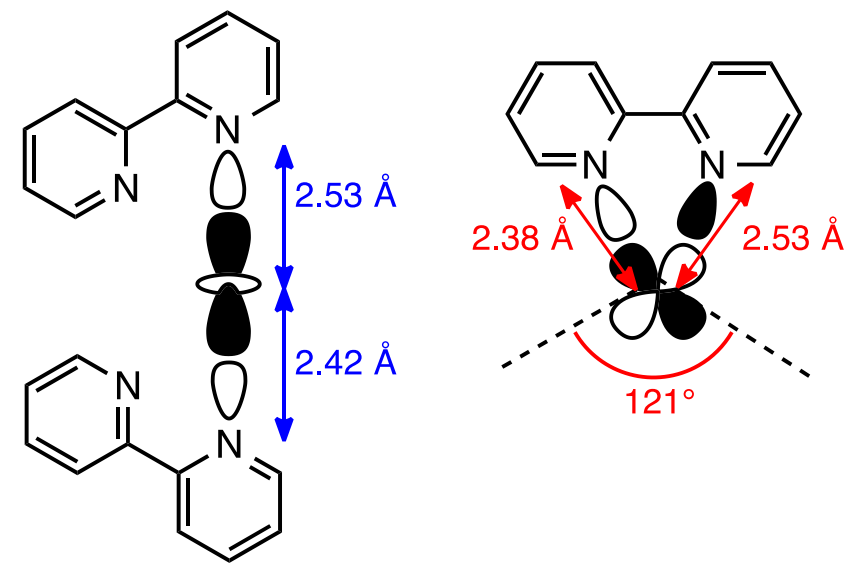

Figure $3 .{ }^{3} \mathrm{MC}$ singly occupied natural orbitals.

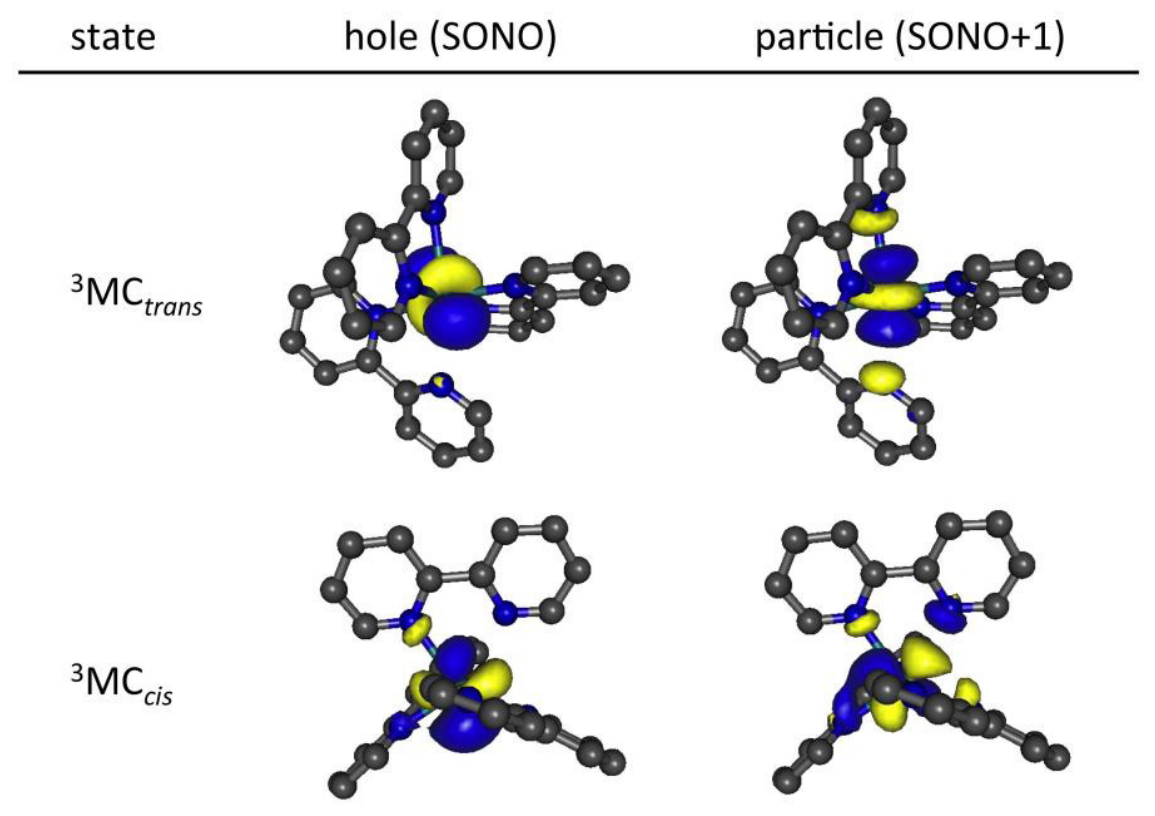

Minimum energy paths (MEPs). We have previously shown that the nudged elastic band (NEB) method, ${ }^{41,42}$ which derives from a chain-of-states approach, ${ }^{47,48}$ is a powerful method to probe the topology of the ${ }^{3} \mathrm{PES} .{ }^{19,21}$ This type of method determines the minimum energy path and provides the 
activation barrier encountered along this MEP, with no apriorism regarding the geometry of a transition state (explicit searching for which is not required). Further confirmation of the quality of the ${ }^{3} \mathrm{MEP}$ computed using the NEB method came from transition state optimization starting from the NEB crests, which converged smoothly at similar energies and geometries. ${ }^{19}$ In this work, MEPs have been computed in solvent between the three triplet excited state minima (Table S2). As schematized in Figure 4, the ${ }^{3} \mathrm{MLCT}-{ }^{3} \mathrm{MC}_{\text {trans }}$ and ${ }^{3} \mathrm{MLCT}-{ }^{3} \mathrm{MC}_{\text {cis }}$ barriers are similar at 9 and $10 \mathrm{kcal} / \mathrm{mol}$ respectively, whilst the ${ }^{3} \mathrm{MC}_{\text {trans }}{ }^{3} \mathrm{MC}_{\text {cis }}$ barrier only amounts to $2 \mathrm{kcal} / \mathrm{mol}$.

Figure 4. Energy profiles for the ${ }^{3} \mathrm{MLCT}^{3}{ }^{3} \mathrm{MC}_{\text {trans }}$ (blue) and ${ }^{3} \mathrm{MLCT}-{ }^{3} \mathrm{MC}_{c i s}$ (red) conversions following two distinct reaction coordinates. The green dashed line schematizes the direct ${ }^{3} \mathrm{MC}_{\text {trans }}{ }^{-}$ ${ }^{3} \mathrm{MC}_{\text {cis }}$ conversion with a $2 \mathrm{kcal} / \mathrm{mol}$ barrier.

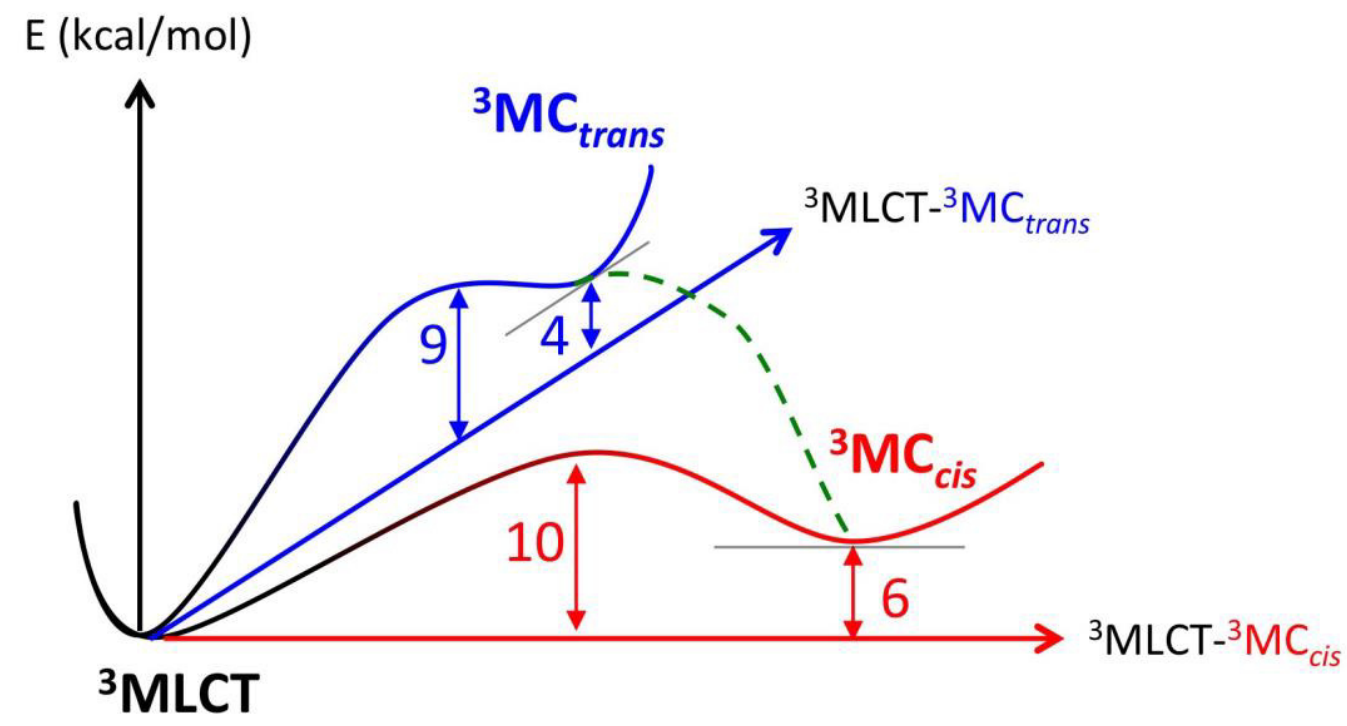

Minimum energy crossing points (MECPs). The existence of singlet/triplet MECPs in the vicinity of a ${ }^{3} \mathrm{MC}$ minimum is well established and provides an efficient nonradiative deactivation funnel. In $\left[\mathrm{Ru}(\mathrm{bpy})_{3}\right]^{2+}$, the MECP between the classical ${ }^{3} \mathrm{MC}_{\text {trans }}$ state and the ground state PES was described in 2009 in vacuum, ${ }^{46}$ lying $7 \mathrm{kcal} / \mathrm{mol}(0.3 \mathrm{eV})$ above the ${ }^{3} \mathrm{MC}$ minimum after further geometrical distortions along the GS $\rightarrow{ }^{3} \mathrm{MC}$ reaction coordinate. This $\mathrm{MECP}$ is called $\mathrm{MECP}_{\text {trans }}$ hereafter. At the current level of theory, $\mathrm{MECP}_{\text {trans }}$ is found $6.2 \mathrm{kcal} / \mathrm{mol}$ above the ${ }^{3} \mathrm{MC}_{\text {trans }}$ minimum. Having now characterized another ${ }^{3} \mathrm{MC}$ state, we also searched for the MECP between this ${ }^{3} \mathrm{MC}_{c i s}$ state and the ground state PES. This crossing point, called $\mathrm{MECP}_{c i s}$, was found to lie only $1.3 \mathrm{kcal} / \mathrm{mol}$ above ${ }^{3} \mathrm{MC}_{c i s}$. The two MECPs are distinct and $\mathrm{MECP}_{\text {cis }}$ is lower in energy than $\mathrm{MECP}_{\text {trans }}$ by $3 \mathrm{kcal} / \mathrm{mol}$. Table $\mathrm{S} 1$ displays selected geometrical parameters and Table S3 displays the singly occupied natural orbitals (SONOs) of the cis and trans ${ }^{3} \mathrm{MECPs}$, showing the orbital parentage between each ${ }^{3} \mathrm{MC}$ minimum and its corresponding MECP. These two MECPs connect the ${ }^{3}$ PES to the reactant GS PES, but others would bring the system further towards photoreactivity, once the system has entered the region where pentacoordinate species are accessible. This was hypothesized in ref. ${ }^{21}$ and further developed in ref. ${ }^{4}$

Impact on the photoreactivity of $\left[\mathbf{R u}(\mathbf{b p y})_{3}\right]^{2+}$. The formation of bis(bipyridine) ligand-loss photoproducts from the reaction of $\left[\mathrm{Ru}(\mathrm{bpy})_{3}\right]^{2+}$ in the presence of coordinating solvents or anions indicates that the complex is able to lose one bpy ligand after photoexcitation, albeit in very low yield under normal experimental conditions. Photoinduced ligand loss is triggered by the population of dissociative excited states. As shown in Figure 1, the classical ${ }^{3} \mathrm{MC}_{\text {trans }}$ state displays two elongated trans $\mathrm{Ru}-\mathrm{N}$ bonds. As such, it does not seem to be prone to lose one bpy ligand, although we may not completely exclude it from all possible photoreactivity mechanisms. On the other hand, the newly 
identified distal ${ }^{3} \mathrm{MC}_{c i s}$ excited state displaying major bond elongations towards a single bpy ligand may be expected to evolve towards photoproducts involving loss of bpy. Mechanistically, the new ${ }^{3} \mathrm{MC}_{c i s}$ is equivalent to previously described flattened ${ }^{3} \mathrm{MC}$ states, ${ }^{4}$ in that it could be the last step before ligand decoordination and diffusion. In any case, the comparative ease with which both ${ }^{3} \mathrm{MC}_{\text {trans }}$ and ${ }^{3} \mathrm{MC}_{\text {cis }}$ states will be populated from the ${ }^{3}$ MLCT state, and the highly accessible MECP for the latter, mean that hitherto unrecognised ${ }^{3} \mathrm{MC}_{c i s}$ states will undoubtedly play a major role in the photophysics and excited state deactivation dynamics of $\left[\mathrm{Ru}(\mathrm{bpy})_{3}\right]^{2+}$ and related complexes.

Conclusion. $\mathrm{A}^{3} \mathrm{MC}$ state displaying one distal bpy ligand was identified and optimized to a minimum for $\left[\mathrm{Ru}(\mathrm{bpy})_{3}\right]^{2+}$. This distal $\mathrm{MC}$ state $\left({ }^{3} \mathrm{MC}_{c i s}\right)$ is destabilized by less than $2 \mathrm{kcal} / \mathrm{mol}$ with respect to the classical MC state $\left({ }^{3} \mathrm{MC}_{\text {trans }}\right)$. The ${ }^{3} \mathrm{MLCT}-{ }^{3} \mathrm{MC}_{\text {trans }}$ and ${ }^{3} \mathrm{MLCT}-{ }^{3} \mathrm{MC}_{\text {cis }}$ barriers are both $\sim 10 \mathrm{kcal} / \mathrm{mol}$ in acetonitrile solution, and the ${ }^{3} \mathrm{MC}_{\text {trans }}{ }^{3} \mathrm{MC}_{\text {cis }}$ barrier is as low as $2 \mathrm{kcal} / \mathrm{mol}$. These figures are larger than those recently reported for photoreactive $\mathrm{Ru}$ bi(triazolyl) derivatives, ${ }^{4}$ in line with the much greater photostability of $\left[\mathrm{Ru}(\mathrm{bpy})_{3}\right]^{2+}$. Nevertheless the very existence of the distal ${ }^{3} \mathrm{MC}_{c i s}$ state as a local minimum, and its accessibility, may have broad implications in our understanding of the photochemistry and photophysics of $\left[\mathrm{Ru}(\mathrm{bpy})_{3}\right]^{2+}$ and related complexes. The lowest ${ }^{3} \mathrm{PES}$ is clearly far more complex than previously appreciated and previous presumptions regarding excited state processes involved in photoreactivity may therefore require some reassessment. At this moment the existence of other ${ }^{3} \mathrm{MC}$ minima cannot be excluded, and we are currently exploring photoreactivity mechanisms in relation with the observed photochemistry of $\left[\mathrm{Ru}(\mathrm{bpy})_{3}\right]^{2+}$.

Supporting Information. Computational details regarding NEB calculations; selected geometrical parameters and total energies; NEB minimum energy paths (MEPs) and Mulliken spin population on Ru along the MEPs; singly occupied natural orbitals for ${ }^{3} \mathrm{MC}$ states and associated MECPs (PDF). Cartesian coordinates (xyz).

\section{AUTHOR INFORMATION}

\section{Corresponding Authors}

* P.I.Elliott@hud.ac.uk

* isabelle.dixon@irsamc.ups-tlse.fr

\section{Author Contributions}

The manuscript was written through contributions of all authors.

\section{Funding Sources}

No competing financial interests have been declared.

\section{ACKNOWLEDGMENT}

We thank the French Ministry for Higher Education and Research for a Ph. D. fellowship to AS. This work was performed using HPC resources from CALMIP (Grant 2017-[p1112]). PE also acknowledges the University of Huddersfield for supporting this work.

\section{REFERENCES}

(1) Thompson, D. W.; Ito, A.; Meyer, T. J. [Ru(bpy) $]_{3}^{2+} *$ and Other Remarkable Metal-to-Ligand Charge Transfer (MLCT) Excited States. Pure Appl. Chem. 2013, 85, 1257-1305.

(2) Englman, R.; Jortner, J. The Energy Gap Law for Radiationless Transitions in Large Molecules. Mol. Phys. 1970, $18,145-164$. 
(3) Göttle, A. J.; Dixon, I. M.; Alary, F.; Heully, J.-L.; Boggio-Pasqua, M. Adiabatic Versus Nonadiabatic Photoisomerization in Photochromic Ruthenium Sulfoxide Complexes: A Mechanistic Picture from Density Functional Theory Calculations. J. Am. Chem. Soc. 2011, 133, 9172-9174.

(4) Dixon, I. M.; Heully, J.-L.; Alary, F.; Elliott, P. I. P. Theoretical Illumination of Highly Original Photoreactive ${ }^{3}$ MC States and the Mechanism of the Photochemistry of Ru(II) Tris(bidentate) Complexes. Phys Chem Chem Phys 2017, 19, $27765-27778$.

(5) Feng, L.; Wang, Y.; Jia, J. Triplet Ground-State-Bridged Photochemical Process: Understanding the Photoinduced Chiral Inversion at the Metal Center of $\left[\mathrm{Ru}(\mathrm{phen})_{2}(\mathrm{~L}-\mathrm{Ser})\right]^{+}$and Its Bipy Analogues. Inorg. Chem. 2017, 56, $14467-14476$.

(6) Van Houten, J.; Watts, R. J. Temperature Dependence of the Photophysical and Photochemical Properties of the tris(2,2'-bipyridyl) Ruthenium(II) Ion in Aqueous Solution. J. Am. Chem. Soc. 1976, 98, 4853-4858.

(7) Durham, B.; Caspar, J. V.; Nagle, J. K.; Meyer, T. J. Photochemistry of Ru(bpy) ${ }_{3}{ }^{2+}$. J. Am. Chem. Soc. 1982, 104, 4803-4810.

(8) Hoggard, P. E.; Porter, G. B. Photoanation of the tris(2,2'-bipyridine) Ruthenium(II) Cation by Thiocyanate. J. Am. Chem. Soc. 1978, 100, 1457-1463.

(9) Thompson, D. W.; Wishart, J. F.; Brunschwig, B. S.; Sutin, N. Efficient Generation of the Ligand Field Excited State of Tris-(2,2'-bipyridine)-ruthenium(II) through Sequential Two-Photon Capture by $\left[\mathrm{Ru}(\mathrm{bpy})_{3}\right]^{2+}$ or Electron Capture by $\left[\mathrm{Ru}(\mathrm{bpy})_{3}\right]^{3+}$. J. Phys. Chem. A 2001, 105, 8117-8122.

(10) Gleria, M.; Minto, F.; Beggiato, G.; Bortolus, P. Photochemistry of Tris(2,2'-bipyridine)ruthenium(II) in Chlorinated Solvents. J. Chem. Soc. Chem. Commun. 1978, 285.

(11) Van Houten, J.; Watts, R. J. Photochemistry of tris(2,2'-bipyridyl) Ruthenium(II) in Aqueous Solutions. Inorg. Chem. 1978, 17, 3381-3385.

(12) Sun, Q.; Mosquera-Vazquez, S.; Lawson Daku, L. M.; Guénée, L.; Goodwin, H. A.; Vauthey, E.; Hauser, A. Experimental Evidence of Ultrafast Quenching of the ${ }^{3}$ MLCT Luminescence in Ruthenium(II) Tris-Bipyridyl Complexes via a ${ }^{3}$ dd State. J. Am. Chem. Soc. 2013, 135, 13660-13663.

(13) Cadranel, A.; Pieslinger, G. E.; Tongying, P.; Kuno, M. K.; Baraldo, L. M.; Hodak, J. H. Spectroscopic Signatures of Ligand Field States in $\left\{\mathrm{Ru}^{\mathrm{II}}\right.$ (imine) $\}$ Complexes. Dalton Trans 2016, 45, 5464-5475.

(14) Mukuta, T.; Fukazawa, N.; Murata, K.; Inagaki, A.; Akita, M.; Tanaka, S.; Koshihara, S.; Onda, K. Infrared Vibrational Spectroscopy of $\left[\mathrm{Ru}(\mathrm{bpy})_{2}(\mathrm{bpm})\right]^{2+}$ and $\left[\mathrm{Ru}(\mathrm{bpy})_{3}\right]^{2+}$ in the Excited Triplet State. Inorg. Chem. 2014, 53, 24812490 .

(15) Mukuta, T.; Tanaka, S. 'ichi; Inagaki, A.; Koshihara, S.; Onda, K. Direct Observation of the Triplet Metal-Centered State in $\left[\mathrm{Ru}(\mathrm{bpy})_{3}\right]^{2+}$ Using Time-Resolved Infrared Spectroscopy. ChemistrySelect 2016, 1, $2802-2807$.

(16) Sun, Q.; Dereka, B.; Vauthey, E.; Lawson Daku, L. M.; Hauser, A. Ultrafast Transient IR Spectroscopy and DFT Calculations of Ruthenium(II) Polypyridyl Complexes. Chem Sci 2017, 8, 223-230.

(17) Durham, B.; Walsh, J. L.; Carter, C. L.; Meyer, T. J. Synthetic Applications of Photosubstitution Reactions of Poly(pyridyl) Complexes of Ruthenium(II). Inorg. Chem. 1980, 19, 860-865.

(18) Vanquickenborne, L. G.; Ceulemans, A. Ligand-Field Models and the Photochemistry of Coordination Compounds. Coord. Chem. Rev. 1983, 48, 157-202.

(19) Soupart, A.; Dixon, I. M.; Alary, F.; Heully, J.-L. DFT Rationalization of the Room Temperature Luminescence Properties of $\mathrm{Ru}(\mathrm{bpy})_{3}{ }^{2+}$ and $\mathrm{Ru}(\mathrm{tpy})_{2}{ }^{2+}:{ }^{3} \mathrm{MLCT}-{ }^{3} \mathrm{MC}$ Minimum Energy Path from NEB Calculations and Emission Spectra from VRES Calculations. Theor. Chem. Acc. Accept.

(20) Göttle, A. J.; Alary, F.; Dixon, I. M.; Heully, J.-L.; Boggio-Pasqua, M. Unravelling the S $\rightarrow$ O Linkage Photoisomerization Mechanisms in Cis- and Trans-[Ru(bpy $\left.)_{2}(\mathrm{DMSO})_{2}\right]^{2+}$ Using Density Functional Theory. Inorg. Chem. 2014, 53, 6752-6760.

(21) Göttle, A. J.; Alary, F.; Boggio-Pasqua, M.; Dixon, I. M.; Heully, J.-L.; Bahreman, A.; Askes, S. H. C.; Bonnet, S. Pivotal Role of a Pentacoordinate ${ }^{3} \mathrm{MC}$ State on the Photocleavage Efficiency of a Thioether Ligand in Ruthenium(II) Complexes: A Theoretical Mechanistic Study. Inorg. Chem. 2016, 55, 4448-4456.

(22) Greenough, S. E.; Roberts, G. M.; Smith, N. A.; Horbury, M. D.; McKinlay, R. G.; Żurek, J. M.; Paterson, M. J.; Sadler, P. J.; Stavros, V. G. Ultrafast Photo-Induced Ligand Solvolysis of Cis-[Ru(bipyridine) $\left.{ }_{2}(\text { nicotinamide })_{2}\right]^{2+}$ : Experimental and Theoretical Insight into Its Photoactivation Mechanism. Phys Chem Chem Phys 2014, 16, $19141-19155$.

(23) Ding, L.; Chung, L. W.; Morokuma, K. Excited-State Proton Transfer Controls Irreversibility of Photoisomerization in Mononuclear Ruthenium(II) Monoaquo Complexes: A DFT Study. J. Chem. Theory Comput. 2014, 10, 668-675.

(24) Camilo, M. R.; Cardoso, C. R.; Carlos, R. M.; Lever, A. B. P. Photosolvolysis of Cis-[Ru( $\alpha$-diimine) $)_{2}(4-$ aminopyridine $\left.)_{2}\right]^{2+}$ Complexes: Photophysical, Spectroscopic, and Density Functional Theory Analysis. Inorg. Chem. 2014, 53, 3694-3708.

(25) Hirahara, M.; Yagi, M. Photoisomerization of Ruthenium(II) Aquo Complexes: Mechanistic Insights and Application Development. Dalton Trans. 2017, 46, 3787-3799.

(26) Tu, Y.-J.; Mazumder, S.; Endicott, J. F.; Turro, C.; Kodanko, J. J.; Schlegel, H. B. Selective Photodissociation of Acetonitrile Ligands in Ruthenium Polypyridyl Complexes Studied by Density Functional Theory. Inorg. Chem. 2015, 54, 8003-8011. 
(27) Arora, K.; White, J. K.; Sharma, R.; Mazumder, S.; Martin, P. D.; Schlegel, H. B.; Turro, C.; Kodanko, J. J. Effects of Methyl Substitution in Ruthenium Tris(2-Pyridylmethyl)amine Photocaging Groups for Nitriles. Inorg. Chem. 2016, 55, 6968-6979.

(28) Nisbett, K.; Tu, Y.-J.; Turro, C.; Kodanko, J. J.; Schlegel, H. B. DFT Investigation of Ligand Photodissociation in $\left[\mathrm{Ru}^{\mathrm{II}}(\mathrm{tpy})(\mathrm{bpy})(\mathrm{py})\right]^{2+}$ and $\left[\mathrm{Ru}^{\mathrm{II}}(\mathrm{tpy})\left(\mathrm{Me}_{2} \text { bpy)(py) }\right]^{2+}\right.$ Complexes. Inorg. Chem. 2018, 57, 231-240.

(29) Salassa, L.; Garino, C.; Salassa, G.; Gobetto, R.; Nervi, C. Mechanism of Ligand Photodissociation in Photoactivable $\left[\mathrm{Ru}(\mathrm{bpy})_{2} \mathrm{~L}_{2}\right]^{2+}$ Complexes: A Density Functional Theory Study. J. Am. Chem. Soc. 2008, 130, 9590-9597.

(30) Salassa, L.; Garino, C.; Salassa, G.; Nervi, C.; Gobetto, R.; Lamberti, C.; Gianolio, D.; Bizzarri, R.; Sadler, P. J. Ligand-Selective Photodissociation from $\left[\mathrm{Ru}(\mathrm{bpy})(4 \mathrm{AP})_{4}\right]^{2+}$ : A Spectroscopic and Computational Study. Inorg. Chem. 2009, 48, 1469-1481.

(31) Borfecchia, E.; Garino, C.; Gianolio, D.; Salassa, L.; Gobetto, R.; Lamberti, C. Monitoring Excited State Dynamics in Cis-[Ru(bpy $\left.)_{2}(\mathrm{py})_{2}\right]^{2+}$ by Ultrafast Synchrotron Techniques. Catal. Today 2014, 229, 34-45.

(32) Marenich, A. V.; Cramer, C. J.; Truhlar, D. G. Universal Solvation Model Based on Solute Electron Density and on a Continuum Model of the Solvent Defined by the Bulk Dielectric Constant and Atomic Surface Tensions. J. Phys. Chem. B 2009, 113, 6378-6396.

(33) Neese, F. The ORCA Program System. Wiley Interdiscip. Rev. Comput. Mol. Sci. 2012, 2, 73-78.

(34) Lee, C.; Yang, W.; Parr, R. G. Development of the Colle-Salvetti Correlation-Energy Formula into a Functional of the Electron Density. Phys. Rev. B 1988, 37, 785-789.

(35) Becke, A. D. A New Mixing of Hartree-Fock and Local Density-Functional Theories. J. Chem. Phys. 1993, 98, $1372-1377$.

(36) Andrae, D.; Haeussermann, U.; Dolg, M.; Stoll, H.; Preuss, H. Energy-Adjusted Ab Initio Pseudopotentials for the Second and Third Row Transition Elements. Theor. Chim. Acta 1990, 77, 123-141.

(37) Weigend, F.; Ahlrichs, R. Balanced Basis Sets of Split Valence, Triple Zeta Valence and Quadruple Zeta Valence Quality for H to Rn: Design and Assessment of Accuracy. Phys. Chem. Chem. Phys. 2005, 7, 3297-3305.

(38) Grimme, S.; Antony, J.; Ehrlich, S.; Krieg, H. A Consistent and Accurate Ab Initio Parametrization of Density Functional Dispersion Correction (DFT-D) for the 94 Elements H-Pu. J. Chem. Phys. 2010, 132 (15), 154104.

(39) Grimme, S.; Ehrlich, S.; Goerigk, L. Effect of the Damping Function in Dispersion Corrected Density Functional Theory. J. Comput. Chem. 2011, 32, 1456-1465.

(40) Allouche, A.-R. Gabedit-A Graphical User Interface for Computational Chemistry Softwares. J. Comput. Chem. 2011, 32, 174-182.

(41) Jonsson, H.; Mills, G.; Jacobsen, K. W. Nudged Elastic Band Method for Finding Minimum Energy Paths of Transitions. In Classical and Quantum Dynamics in Condensed Phase Simulations; Berne, B. J., Cicotti, G., Coker, D. F., Eds.; World Scientific, 1998; pp 385-404.

(42) Henkelman, G.; Jóhannesson, G.; Jónsson, H. Methods for Finding Saddle Points and Minimum Energy Paths. In Theoretical Methods in Condensed Phase Chemistry; Schwartz, S. D., Ed.; Kluwer Academic, 2000; pp 269-300.

(43) Herbol, H. C.; Stevenson, J.; Clancy, P. Computational Implementation of Nudged Elastic Band, Rigid Rotation, and Corresponding Force Optimization. J. Chem. Theory Comput. 2017, 13, 3250-3259.

(44) Smidstrup, S.; Pedersen, A.; Stokbro, K.; Jónsson, H. Improved Initial Guess for Minimum Energy Path Calculations. J. Chem. Phys. 2014, 140, 214106.

(45) Alary, F.; Heully, J.-L.; Bijeire, L.; Vicendo, P. Is the ${ }^{3}$ MLCT the Only Photoreactive State of Polypyridyl Complexes? Inorg. Chem. 2007, 46, 3154-3165.

(46) Heully, J.-L.; Alary, F.; Boggio-Pasqua, M. Spin-Orbit Effects on the Photophysical Properties of Ru(bpy) ${ }_{3}{ }^{2+} . J$. Chem. Phys. 2009, 131, 184308.

(47) Liotard, D.; Penot, J.-P. Critical Paths and Passes: Application to Quantum Chemistry. In Numerical methods in the study of critical phenomena; Della Dora, J., Demongeot, J., Lacolle, B., Eds.; Springer, 1981; pp $213-221$.

(48) Liotard, D. A. Algorithmic Tools in the Study of Semiempirical Potential Surfaces. Int. J. Quantum Chem. 1992, 44, 723-741. 


\section{TOC graphic}

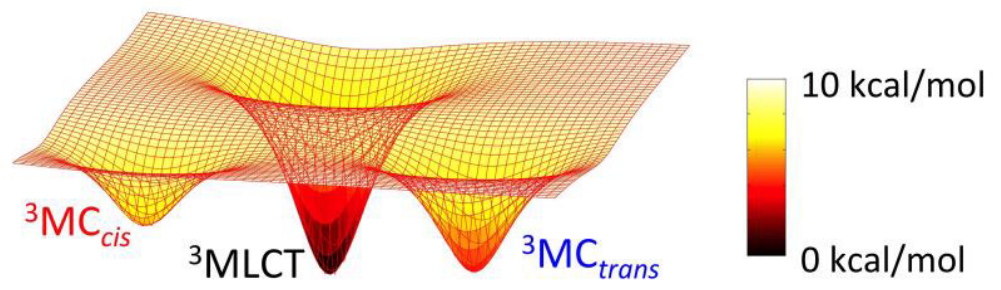

A new ${ }^{3} \mathrm{MC}$ minimum displaying bond elongations towards a single ligand is described $\left({ }^{3} \mathrm{MC}\right.$ cis). According to NEB calculations of the minimum energy paths, this new state is equally accessible from the ${ }^{3} \mathrm{MLCT}$ state than the well-known $\mathrm{dz}^{2}$-like ${ }^{3} \mathrm{MC}$ state $\left({ }^{3} \mathrm{MC}\right.$ trans $)$. This new electronic excited state should be relevant in the photodecomposition of $\mathrm{Ru}(\mathrm{bpy})_{3}{ }^{2+}$. 